\title{
RAZONES EPISTÉMICAS Y NO EPISTÉMICAS EN LA ADMISIÓN DE LA PRUEBA TESTIFICAL EN EL PROCESO PENAL PERUANO
}

\section{Epistemic and non-epistemic reasons for the admission of testimonial proof in the Peruvian Criminal Procedure}

Raquel Limay Chavez*

Pontificia Universidad Católica del Perú

Profesora en la Facultad de Derecho de la Pontificia Universidad Católica del Perú. Magister en Razonamiento Probatorio en la Universidad de Girona (España) y Universidad de Génova (Italia). Con estudios de Maestría en Ciencias Penales en la Universidad Nacional Mayor de San Marcos y en el Programa Internacional de Especialización en Argumentación Jurídica de la Universidad de Alicante. Abogada por la Universidad Nacional Mayor de San Marcos. Secretaria de confianza de la Corte Suprema de Justicia de la República del Perú. ORCID iD: 0000-0001-9278-1067. Contacto: r.limay@pucp.edu.pe 


\section{Resumen:}

El presente trabajo se enfoca en el análisis de las razones epistémicas y no epistémicas de las reglas de admisión de la prueba testimonial en el Código Procesal Penal de 2004. Las primeras atienden al reconocimiento del principio de relevancia como criterio rector de admisión probatoria, que implica que se incorpore todo testimonio que contribuya al esclarecimiento de los hechos. Las segundas, orientadas a la protección de valores distintos que se constituyen en la base para excluir testimonios relevantes, serán evaluadas a fin de determinar si están adecuadamente justificadas. Se plantea una propuesta de regulación de la prueba testimonial acorde a los fines epistémicos de la prueba.

\section{Abstract:}

This paper focuses on the analysis of the epistemic and non-epistemic reasons of the admission rules for testimonial proof in the 2004 Criminal Procedure Code. The first reasons address the recognition of the principle of relevance as the guiding criterion for admission of proof, which implies that all testimony that contributes to the clarification of the facts is incorporated. The second reasons, aimed at the protection of different values which are the basis for excluding relevant testimonies, will be evaluated to determine whether these exclusions are adequately justified. This research presents a proposal for the regulation of testimonial proof according to the epistemic purposes of the proof

\section{Palabras claves:}

Admisión - inadmisión - Prueba - Relevancia - Testimonio - Razón epistémica - Verdad

\section{Keywords:}

Admission - inadmissibility - Proof - Relevance - Testimony - Epistemic reason - Truth

\section{Sumario:}

1. Introducción - 2. Orientación epistémica de la fase de admisión probatoria en el CPP - 3. Regulación normativa de la admisibilidad probatoria en el CPP - 4. Identificación del problema - 5. Conclusiones - 6. Lista de referencias 


\section{INTRODUCCIÓN}

La etapa o fase de admisión de pruebas del proceso penal se encuentra consagrada en los artículos 155 y 352.5 del Código Procesal Penal de 2004 (en adelante, CPP), que regulan los criterios de admisión aplicables para todos aquellos medios de prueba que, propuestos por las partes, pretendan ingresar al proceso para ser actuados y valorados.

La decisión de admitir o no un medio de prueba concreto se constituye en uno de los poderes probatorios que ejerce el juez de la investigación preparatoria. Es un poder probatorio judicial porque otorga al órgano jurisdiccional la potestad de decidir qué elementos de prueba deberán ser ingresados y cuáles serán rechazados. La presente investigación aborda este poder de admisión/ inadmisión en el proceso penal, pero de un medio de prueba en específico: la prueba testifical o testimonial.

De acuerdo con los criterios generales de admisión previstos en los mencionados artículos 155 y 352.5 del CPP, todo testimonio que ingrese al proceso judicial deberá ser útil, pertinente, conducente y no vulnerar los derechos fundamentales de las personas. A lo largo del trabajo se verá que los criterios de utilidad, pertinencia y conducencia implican que todo testimonio que integre el sustrato probatorio deberá ser relevante para demostrar o refutar la hipótesis del caso (objeto de prueba). Esto significa que los mencionados presupuestos generales de admisión poseen un mismo contenido conceptual vinculado con la relevancia de la prueba y su inclusión.

En ese sentido, el principio general que rige la fase de admisión será el de relevancia probatoria, principio de naturaleza epistémica en tanto que, a través de su vigencia y aplicación, se promueve el ingreso de todo testimonio relevante (esto es, vinculado con el objeto de prueba). La inclusión o incorporación al proceso de todo testimonio que cumpla con este presupuesto generará decisiones más acertadas y cercanas a la verdad.

Ahora bien, la prueba testimonial, conforme está prevista en el CPP, contempla diversos criterios o reglas específicas de admisión/inadmisión; algunas que siguen el fin epistémico y otras que poseen un fundamento contrario al principio de relevancia, excluyendo testimonios altamente útiles para el esclarecimiento de los hechos. La exclusión de declaraciones se fundamenta en razones distintas a la búsqueda de la verdad que responden, por ejemplo, a la protección de valores importantes. El problema identificado se relaciona con aquellas reglas de la prueba testimonial que prescinden o contradicen la finalidad epistémica que orienta la admisión de pruebas y que no se encuentran adecuadamente justificadas. 
En el presente trabajo, se evidencian los artículos que regulan la prueba testimonial en el CPP, que son contrarios al principio epistémico de relevancia o inclusión, y que no poseen una base sólida sobre la que se funde su exclusión; por ello, se tiene como objetivo establecer una propuesta de regulación de la prueba testimonial acorde a los fines epistémicos de la prueba. En ese sentido, se plantea como hipótesis que la regulación normativa debe promover la inclusión de todo testimonio relevante para el esclarecimiento de los hechos.

\section{ORIENTACIÓN EPISTÉMICA DE LA FASE DE ADMISIÓN PROBATORIA EN EL CPP}

El proceso judicial es, por naturaleza, un proceso cognoscitivo porque, precisamente, está orientado al conocimiento de los hechos, a averiguar lo que sucedió en la realidad; esa es su finalidad y es la que orienta cada una de sus fases o momentos procesales (la admisión, la práctica y la valoración). Si bien se ha discutido sobre la orientación que puede tener nuestro CPP en materia probatoria, se puede señalar que la etapa de admisión se orienta bajo un fin epistémico que implica que la decisión sobre admisibilidad de todo elemento de juicio está comprometida con el esclarecimiento de los hechos.

Comprender el fin epistémico del proceso involucra reconocer la existencia de una relación teleológica entre proceso y verdad, y entre prueba y verdad (Ferrer, 2005, p. 31; De Paula Ramos, 2013, p. 288). La finalidad institucional del proceso y la prueba se dirige a un fin primordial que es la búsqueda o determinación de la verdad. Esta última entendida como correspondencia con la realidad (Ferrer, 2005, p. 73).

Como la fase de admisión de prueba se orienta bajo un fin epistémico (determinar la verdad de los enunciados sobre los hechos), esta fase tendrá como principio fundamental al criterio de relevancia, que se erige como orientador de la fase de admisión, que promueve la incorporación de toda prueba que contribuya a esclarecer la hipótesis fáctica formulada o el objeto de prueba establecido. Esta decisión de inclusión conlleva a que, cuantos más elementos de prueba - siempre relevantes - sean ingresados al proceso, exista una mayor probabilidad que los hechos se esclarezcan con mayor precisión y que el juez tenga mayor opción de elegir la hipótesis probablemente verdadera.

El principio de relevancia implica que todo elemento relevante debe incluirse dentro del sustrato probatorio y que, a mayor ingreso de elementos relevantes al sustrato probatorio, mayor será el éxito de obtener la verdad. 
Seguidamente, se analizará con mayor detalle la fase de admisión en el esquema procesal penal peruano y luego el reconocimiento del principio de relevancia en los criterios de admisión de pruebas previstos en el CPP.

\section{REGULACIÓN NORMATIVA DE LA ADMISIBILIDAD PROBATORIA EN EL CPP}

\subsection{La fase de admisibilidad en el esquema procesal peruano}

Ferrer (2017, pp. 150-158) diferencia hasta seis formas en que el juez puede ejercer sus poderes, entre ellas: i) la potestad de admitir o inadmitir pruebas propuestas por las partes; ii) la capacidad de intervenir en la práctica de la prueba; iii) la potestad de indicar a las partes la existencia de lagunas probatorias que deberían ser integradas por pruebas específicas que no fueron aportadas por los sujetos procesales; iv) la capacidad de disponer que se incluyan pruebas no solicitadas por las partes (prueba de oficio); v) el poder que posee de alterar la carga de la prueba durante el desarrollo del proceso (carga dinámica de la prueba); y, finalmente, el poder probatorio de mayor intensidad y repercusión para el proceso, vi) decidir qué hipótesis fácticas se considerarán probadas.

Algunos de los poderes mencionados se pueden identificar en el CPP. Así, el poder de admisión/inadmisión de pruebas se encuentra previsto en los artículos 155 y 352, la práctica o actuación de las pruebas está prevista desde el artículo 375 hasta el 385, y el poder de incorporación de oficio de pruebas no solicitadas por las partes halla su regulación en el artículo 385.2; mientras que el resultado de la valoración judicial de las pruebas (elección de la hipótesis), así como los criterios empleados por el órgano para su decisión, está contemplado en el artículo 158.1 de la normativa procesal penal.

La decisión de admitir o no una prueba es el primer poder que ejerce el juez en materia probatoria.

Posterior a la proposición de elementos de prueba presentados por las partes, corresponde la evaluación por el juez de la investigación preparatoria de decidir si se admiten o se excluyen pruebas del caudal probatorio que formará y que posteriormente serán valoradas en el juicio oral. Solo se practican y valoran aquellas pruebas que han sido admitidas previamente.

Como bien lo señala Taruffo (2011, p. 364), la admisión es el primer momento en el que entra en juego la regulación jurídica de la prueba, se trata de decidir qué elementos de prueba pueden ser empleados en el proceso. Es 
una fase trascendental porque solo a través de la decisión admisoria se forma el sustrato probatorio.

La importancia de la fase de admisibilidad se encuentra focalizada en la delimitación del campo probatorio (formada por los elementos de juicio), ejercida por el actor de dicha etapa: el juez. Como lo indica Abel, "se decide el material que accederá a las actuaciones y que constituirá el sustrato probatorio" (2012, p. 272), además de determinar qué elementos propuestos deberán ser excluidos por incurrir en algunos de los supuestos legales que impidan su introducción al proceso.

La regulación procesal penal peruana enmarcada en el sistema del civil law posee como notas características que la etapa de admisión la dirige un juez profesional en derecho, conocido como el "juez de la investigación preparatoria" o "juez de garantías" (Del Río, 2010, p. 60), y un órgano jurisdiccional distinto del tribunal encargado de la fase del juicio, también integrado por jueces profesionales; en ambos casos, los jueces tienen el deber de motivar adecuadamente sus decisiones.

La regulación normativa de la prueba y su actividad responde -entre otras razones- a la configuración del sistema procesal, que puede clasificarse en dos grandes grupos: el civil law y el common law. Sobre el civil law, se ha sostenido que tiende a "regular todo el fenómeno de las pruebas y a excluir del mismo todo lo que esté fuera de esta regulación"; por esta configuración, ha sido considerado como un modelo formalista cerrado, en tanto que "es renuente que recurra a modelos epistemológicos y reglas racionales provenientes de otros sectores de la experiencia" (Gascón, 2006, p. 50).

Por otro lado, el sistema de common law se estima como uno abierto porque contiene una regulación mínima de la actividad probatoria. Gascón y Taruffo argumentan que en este sistema rige la freedom of proof (libertad de prueba), lo que genera que se establezcan, como excepciones, determinadas reglas de exclusión en la fase admisoria. Adicional a ello, a diferencia del sistema del civil law, "la regulación probatoria sí se apoya en los modelos epistemológicos y reglas racionales tomados de otros sectores de la experiencia" (Gascón, 2006, p. 51).

Precisamente, este contexto no se observa en las regulaciones de algunos países del common law que cuentan con un juez que analiza y decide el ingreso de pruebas en la etapa de admisibilidad probatoria y un jurado para el momento del juicio. Este sistema centra, esencialmente, su atención en la fase de admisibilidad (Taruffo, 2011, p. 361), a diferencia del sistema peruano, perteneciente al civil law, donde el foco de atención es la etapa de valoración 
probatoria. En el primero, la creación de las reglas de admisibilidad suele ser vista como "una técnica probatoria para controlar la calidad de la información con que decidirá el juzgador de los hechos" (Vázquez, 2015, p. 103) que funda su razonamiento en factores subjetivos como su íntima convicción o conocimiento en conciencia ${ }^{1}$.

Como lo refiere Ferrer (2017, pp. 163-164), estas reglas tendrían el objetivo de evitar que, en la valoración de las pruebas, dado que los jurados no conocen de derecho, le otorguen un valor excesivo o mínimo a las pruebas que evalúan. De cierto modo, estas reglas pretenden garantizar ex ante que las decisiones sean racionales, decisión que puede implicar incluso la exclusión de pruebas que aportan informaciones relevantes.

Por su parte, en el sistema de civil law, el control de las decisiones se realiza en la fase de valoración y se controla mediante la motivación. La valoración de la prueba se encuentra regida bajo las reglas del sistema de sana crítica (artículo 158 del Código Procesal Penal de 2004) y el "criterio de conciencia" (esta última terminología es empleada en el artículo 283 del Código de Procedimientos Penales de 1940 aplicado en algunos de los distritos judiciales del Perú).

\subsection{Criterios de admisibilidad en el CPP}

La etapa de admisión probatoria posee la siguiente configuración normativa, según lo previsto en el artículo 155.2 del CPP:

Las pruebas se admiten a solicitud del Ministerio Público o de los demás sujetos procesales. El juez decidirá su admisión mediante auto especialmente motivado, y sólo podrá excluir las que no sean pertinentes y prohibidas por la Ley. Asimismo, podrá limitar los medios de prueba cuando resulten sobreabundantes de modo manifiesto o de imposible consecución [Énfasis agregado].

Esta fase probatoria se complementa con lo dispuesto en el artículo 352.5 del mismo cuerpo de leyes, que estipula que la admisión de los medios de prueba ofrecidos requiere [Énfasis agregado]:

- Que la petición contenga la especificación del probable aporte a obtener para el mejor conocimiento del caso; $y$

- Que el acto probatorio propuesto sea pertinente, conducente y útil.

\footnotetext{
$1 \quad$ Aunque ello no niegue que los sistemas continentales también tengan reglas de valoración
} fundadas en la íntima convicción o certezas. 
En función del contenido normativo de la etapa de admisión, San Martín Castro (2020, p. 833) la define como el acto del juez por el que, previo examen de los requisitos necesarios, determina cuáles serán los medios de prueba a ser practicados en el proceso penal. Agrega que el acto de admisión debe fundarse en la observancia de los requisitos i) específicos, es decir, aquellos previstos en cada medio de prueba en concreto; o ii) de carácter general, que precisamente son regulados por las citadas normas. En ese sentido, podrán admitirse los medios de prueba previstos legalmente y aquellos que comporten licitud en el procedimiento de obtención de las fuentes de prueba. El citado profesor sostiene que la condición de admisibilidad de pruebas depende del cumplimiento de los requisitos de pertinencia y necesidad, así como de conducencia y no sobreabundancia.

En esa línea de análisis, la fase de admisión se trata del acto del tribunal, o del juez en el sistema procesal peruano, por la cual, previo examen de los requisitos necesarios y fijados en la norma, se determina los medios de prueba - propuestos por las partes - que deberían practicarse en el proceso (Montero, 2000 , p. 291). Para llegar a esta fase, por supuesto, se requiere de la previa proposición de los medios de prueba y la fijación de los hechos controvertidos (lo que será el objeto de prueba) $)^{2}$. Ello implica que, sin la previa proposición, el juez no puede emitir su juicio de admisión o inadmisión de prueba (Abel, 2012, p. 271).

Respecto a su procedimiento, el control de admisión se realiza en audiencia pública durante la etapa intermedia del proceso penal peruano. En dicha audiencia preliminar, concurren todas las partes procesales que proponen ante el juez determinados medios de prueba que consideren que cumplan con los supuestos exigidos legalmente. En primer lugar, fundamentan la pertinencia de cada medio de prueba con el caso materia de discusión; seguidamente, la contraparte podrá cuestionar dicha pertinencia y será finalmente el juez de investigación preparatoria quien decida si el medio de prueba ingresa o no al caudal probatorio (artículo 351.3 del CPP).

La decisión de admisión se toma en el acto, luego de escuchar a la parte que propone la prueba y a la parte que contradice o tiene alguna observación al ingreso de esta. Específicamente, el artículo 351.3 del CPP dispone que el

La fijación de los hechos controvertidos no se refiere a la clásica postura de Carnelutti sobre la prueba, según la cual afirmaba que probar no es demostrar la verdad de los hechos discutidos, sino que se trata de fijar formalmente los hechos mismos a través de procedimientos regulados por el proceso penal, situándose, por ejemplo, las reglas de admisión (Cuello, 2008, p. 382). 
juez debe otorgar la palabra por un tiempo corto, en el siguiente orden: al fiscal, a la defensa técnica del actor civil, así como al abogado del acusado y del tercero civilmente responsable. Son estos sujetos procesales quienes discutirán sobre la procedencia o admisibilidad de cada una de las pruebas propuestas. La decisión judicial es célere, pero posteriormente se plasma en el auto que dispone el enjuiciamiento y con el cual se impide la entrada de nuevos elementos de prueba.

Ahora bien, como se ha sostenido, uno de los objetivos que se pretende conseguir con el control de admisibilidad es que la prueba que ingresará cumpla con los requisitos dispuestos normativamente, estos se constituyen en una especie de "salvoconducto" que permite que las pruebas transiten desde la proposición a la práctica (Contreras, 2015, p. 41) y que sean solo dichas pruebas las que ingresen y formen parte del sustrato probatorio.

Los criterios generales de admisión dispuestos taxativamente en el CPP son los siguientes:

\subsubsection{La pertinencia}

El Tribunal Constitucional peruano, en el Expediente $\mathrm{N}^{\circ}$ 02333-2004-HC/ TC, ha destacado lo siguiente:

[E]I derecho a la prueba se encuentra sujeto a determinados principios, de tal modo que su ejercicio se realice de conformidad con los valores de pertinencia, utilidad, oportunidad y licitud. Estos se erigen en principios de la actividad probatoria y, al mismo tiempo, en límites a su ejercicio, derivados de la propia naturaleza del derecho [Énfasis agregado].

Este supremo órgano precisa que una prueba es pertinente cuando "resulta indispensable para la resolución de la pretensión de declaración judicial $y$, especialmente, para resolver los puntos controvertidos fijados en el proceso judicial" (fundamento 4 del Expediente $N^{\circ}$ 00227-2011-PA/TC). Por su parte, la Corte Suprema, en la Casación N³17-2018-Ica (fundamento 9), sostuvo que la pertinencia de la prueba "está vinculada con la relación del medio de prueba y los hechos objeto del debate".

La literatura procesal ha identificado a la pertinencia como aquel presupuesto de admisión que determina la relación que guarda el medio de prueba con el objeto del proceso (Abel, 2012, p. 281). Oré refiere que la pertinencia exige que la prueba que se ofrece debe mantener una relación lógica con el hecho que se pretende probar (2016, p. 343). 
Taruffo (2011, p. 38) define que una información es pertinente "si, y solo sí, permite fundar en él - por sí solo o conjuntamente con otros elementos- una conclusión sobre la verdad del enunciado fáctico a probar". De esta definición se pueden desprender dos elementos: "a) la relación (directa o indirecta) con el tema de prueba y b) la posible influencia en la toma de decisión sobre los hechos" (Vázquez, 2017, p. 360).

La relación es directa cuando existe una clara vinculación entre la prueba presentada y lo que se pretende probar. Por ello, se recomienda que la decisión del juez, sobre la pertinencia de la prueba, no debe ser acelerada en tanto no solo deberá admitir las pruebas que tengan relación directa con el objeto a ser probado, sino también evaluar el grado de relación que posean todos los elementos a ser probados (Parra, 2013, p. 153).

El presupuesto de pertinencia ha recibido también otras denominaciones; por ejemplo, Duce (2013, p. 157) la califica como "relevancia lógica" y la entiende como aquella vinculación de contenido de dicha prueba con los hechos a debatir en juicio. Esta misma denominación es adoptada por Parra (2013, p. 153).

Revisada la interpretación del presupuesto de pertinencia otorgado por la jurisprudencia y doctrina se aprecia que, si bien pueden variar su denominación, su contenido es similar a los demás presupuestos que se verán seguidamente, es decir, una prueba pertinente será aquella que sea útil o conduzca a demostrar el objeto de prueba. Por tal razón, no requiere mayor diferenciación con los demás supuestos de admisión previstos en la norma, es decir, con la conducencia y utilidad, pues todos estos presuponen la exigencia de que todo elemento ingresado al proceso necesariamente tenga una vinculación con los hechos que es necesario probar para verificar la verdad (en similar sentido, Jauchen, 2004, p. 28). En palabras del Tribunal Supremo, en la Sentencia $N^{\circ}$ $3191 / 2020$, la Sentencia que la prueba tenga funcionalidad con los hechos a probar (10 de octubre, 2020).

\subsubsection{La conducencia}

La Corte Suprema, en la Casación N³17-2018-Ica (fundamento 9), precisó que el criterio de conducencia se relaciona con la legalidad de la prueba. En la doctrina nacional peruana se identifica este requisito de admisión como "idoneidad legal"; en ese sentido, se ha señalado que la conducencia es una cuestión o materia de derecho porque consiste en determinar si el medio de prueba a emplearse, presentado o solicitado es apto para probar el hecho (Talavera, 2009, p. 57). Bajo ese entender, la conducencia se vincula con la aptitud 
del elemento para probar el hecho. Esta aptitud tendría que ver con la carga de las partes del proceso de que el medio de prueba que presenten se ajuste a las exigencias legales (tiempo y forma) previstas (Contreras, 2015, p. 42).

Montero (2000, pp. 291-292) refiere que una prueba que no siga la correspondiente actividad probatoria prevista en la normativa no podrá ser admitida por constituirse en una actividad ilegal, dado que, si bien existe libertad probatoria y el ingreso de toda fuente de prueba es libre, no lo será si no atiende a la regulación para su ingreso. El citado autor describe que la admisión de una prueba dependerá del cumplimiento de las formas establecidas por la ley; por ejemplo, si la norma prevista para la declaración de un testigo exige su concurrencia con la finalidad de que, posteriormente, pueda ser sometido a contradicción y valorarse su declaración adecuadamente por el juez, entonces la parte que lo proponga no podría presentar la declaración en un acta notarial.

El requisito de conducencia de la prueba, interpretado en el sentido expuesto, enuncia una de las limitaciones procesales fijadas por el legislador para la admisión de pruebas: que, aun al ser pertinentes, no pueden ser incorporadas a la base probatoria por incumplimiento de las formas y modos que regula y exige el ordenamiento jurídico. Por su parte, el Tribunal Constitucional, en el Expediente $\mathrm{N}^{\circ} 6712-2005-\mathrm{HC} / \mathrm{TC}$, ha interpretado que la inconducencia o no idoneidad del medio probatorio se determinará cuando se encuentre prohibido: a) en determinada vía procedimental o b) para verificar un determinado hecho. Esto significa que se adoptan dos interpretaciones de este presupuesto. En primer lugar, que exija el cumplimiento de las formas procedimentales; y, en segundo lugar, si está relacionada con su característica de pertinencia para determinar los hechos de la causa.

De esta segunda disquisición, se puede concluir que la conducencia en el segundo sentido también se vincula elementalmente al criterio de pertinencia porque posee el mismo contenido; por ende, en adelante, no será necesario establecer una diferencia con este último requisito admisorio porque, tanto la pertinencia como la conducencia (en una de sus interpretaciones), será la característica de aquella prueba que se vincule con el objeto de prueba.

\subsubsection{La utilidad}

El Tribunal Constitucional en el Expediente $N^{\circ} 1014-2007-\mathrm{PHC} / \mathrm{TC}$ ha precisado que la utilidad se trata "de una característica que vincula directamente a la prueba con el hecho presuntamente delictivo" [Énfasis agregado], y añade que se confirmará la utilidad de la prueba siempre y cuando produzca "certeza en el juez" para la resolución o aportación a la resolución del caso concreto. 
No obstante, en un caso diferente precisó que la utilidad de la prueba se trata de un valor y principio que forma parte del derecho a la prueba (Expediente $\mathrm{N}^{\circ}$ 01601-2013-PHC/TC).

Por su parte, la Corte Suprema en la Casación N³17-2018 relaciona el requisito de utilidad de la prueba con el "contenido del aporte que se espera alcanzar de esta"; también el Recurso de Nulidad N 1435-2019 refirió que "la acreditación de los hechos objeto del proceso se obtienen sobre la base de todas las pruebas que han sido incorporadas al caso y que se hayan revelado esenciales y útiles para establecer los hechos de la causa" [Énfasis agregado].

La jurisprudencia expuesta tanto del Tribunal Constitucional como de la Corte Suprema vinculan el presupuesto admisorio de utilidad con el aporte que brinda la prueba al objeto que se pretende probar, es decir, respondería a la pregunta de cuánto puede cambiar - positiva o negativamente- la hipótesis si se agregara o eliminara dicho medio de prueba.

En la doctrina procesal, el presupuesto de utilidad de prueba es analizado del siguiente modo. Talavera $(2009$, p. 216) refiere que una prueba será útil cuando "contribuya a conocer lo que es fijado como objeto de prueba y se oriente a descubrir la verdad, a alcanzar probabilidad o incluso la certeza". Asimismo, Oré $(2016$, p. 345) refiere que "la utilidad informa que la prueba debe ser relevante para descubrir el hecho principal o secundario que forma parte del objeto del proceso". Armenta (2012, p. 182), por su parte, sostiene que una "prueba inútil o inconducente es aquella que, según las reglas y criterios razonables y seguros, en ningún caso puede contribuir a esclarecer los hechos controvertidos".

\subsubsection{La relevancia de la prueba}

Expuestos los presupuestos de admisión de pertinencia, conducencia y utilidad, se aprecia que, en concreto, los tres implican que toda prueba, para ser ingresada al proceso, debe generar un cambio sea de confirmación o refutación de la hipótesis del caso (probandum final u objeto de prueba). Esto significa que, para que una prueba sea catalogada como pertinente, conducente y útil, debe poseer relevancia para el caso. La relevancia es, entonces, el presupuesto base de todo juicio de admisión probatoria.

La relevancia es un principio de la actividad de admisión y debe ser interpretada de conformidad el contenido previsto en los artículos 155 y 352.5.a del $\mathrm{CPP}$, este último indica que el ofrecimiento del medio de prueba debe contener el específico y probable aporte que generará al sustrato probatorio, siempre 
con el fin de lograr el "mejor conocimiento del caso"3. . Dei Vecchi (2019, p. 163) afirma, por ejemplo, lo siguiente:

Ante todo esto, hay un criterio epistémico en particular que se torna crucial, a saber: el de relevancia de la prueba, a veces denominado en el derecho procesal pertinencia. Se trata de una noción compleja que puede ser esbozada a efectos de esta ponencia del siguiente modo: una prueba es relevante si tenerla en cuenta cambia el estatus de justificación epistémica de la proposición en cuestión. Por el contrario, una prueba es irrelevante si incluirla en el conjunto de elementos de juicio no altera de ningún modo el estatus de justificación epistémica de esa proposición.

En otras palabras, la relevancia de una prueba determina que su ingreso esclarezca en mayor medida los hechos objeto de debate y posee su fundamentación en la concepción epistemológica de la verdad como finalidad del proceso y la prueba. Sobre ello, Vázquez (2015, p. 102) sostiene que:

El criterio fundamental para decidir la admisibilidad de una prueba es, pues, su relevancia (o, si prefiere, su pertinencia) y esta está relacionada con la probabilidad de acierto en la decisión. Es decir, el aumento de información relevante puede aumentar la probabilidad de la hipótesis, pero puede disminuirla o incluso no alterarla; sin embargo, pareciera que algo aumenta si disponemos de más información, pues se tiene una base más sólida para fundar la conclusión (Keynes, 1920, p. 71).

De la regulación de criterios de admisión previstos en el CPP, es posible identificar que la fase de admisión está orientada por una finalidad epistémica, es decir, de búsqueda de la verdad, como fin institucional del proceso y de la prueba en el que rige el principio de relevancia que prioriza la inclusión de todo elemento de prueba relevante.

\section{IDENTIFICACIÓN DEL PROBLEMA}

Si bien las normas de admisión de pruebas se fundamentan en el principio epistemológico de relevancia, que permite concluir que todo elemento de

3 Así, por ejemplo, el Juzgado de Investigación Preparatoria de la Corte Suprema en el auto de enjuiciamiento-control de acusación Resolución № 16 del 5 de noviembre de 2018 del Expediente $N^{\circ}$ 07-2016, indicó que "se cumplió con indicar la conducencia, pertinencia y utilidad - tal como se oralizó en audiencia pública, además, guardan relación con la imputación contenida en el requerimiento fiscal oralizado en esta audiencia preliminar de control de acusación (...) deben admitirse porque fueron ofrecidos en el plazo establecido en el artículo 350 del Código Procesal Penal; guardando relación con el thema probandum". 
prueba, como el testimonio, que contribuye al esclarecimiento de los hechos, deberá ser incluido en el proceso, las normas específicas que regulan la prueba testimonial contienen excepciones a la admisión de testimonios que son potencialmente relevantes. Algunas de las excepciones se fundamentan en razones no epistémicas que responden a la protección de valores diferentes a la búsqueda de la verdad y que se aplican para excluir testimonios importantes, empobreciendo el sustrato probatorio y alejando al juez de esclarecer la verdad.

A continuación, se analizará la normativa procesal penal que regula de forma concreta la prueba testimonial, se identificará la orientación epistémica y no epistémica de cada uno de los artículos, se analizará la justificación de aquellos de índole no epistemológica. En principio, se considera que alguno de estos constituye exclusiones del testimonio indebidamente justificados y se planteará como hipótesis que, en función de la prevalencia del principio de relevancia o inclusión de pruebas, todo testimonio que permita esclarecer en mayor medida los hechos discutidos en el proceso penal debe ser admitido; así, se rechaza la indebida exclusión de determinados testimonios que prevé el CPP.

\subsection{Exclusión de testimonios en el CPP. Razones epistémicas y no epis- témicas}

La prueba testifical o testimonial se encuentra regulada en los artículos 162 al 171 del CPP. Este sustento normativo sostiene como regla general que toda persona es hábil para prestar testimonio. No obstante, seguidamente se detalla una serie de excepciones a esta regla que serán analizadas a continuación con el fin de determinar si están debidamente justificadas.

Para un mejor análisis y evaluación de las reglas del CPP que excluyen testimonios se clasificarán del siguiente modo: primero, se analiza las excepciones por la condición del testigo, dentro de las cuales se encuentran los testigos impedidos por razones naturales y los impedidos por ley; segundo, se aborda la exclusión del testimonio por el tipo de información que el testigo puede revelar.

\subsubsection{Excepciones por la condición del testigo}

\section{i. Testigos impedidos por razones naturales}

EI CPP prevé que no puede proponerse como testigos en el proceso penal a personas que carecen de idoneidad física o psíquica necesaria para declarar. La norma expresa que, de presentarse estos casos, y al momento de la valoración de su testimonio, se pueden realizar las pericias que correspondan (artículo 
162.2 del CPP) para confirmar la idoneidad del testigo. Esta pericia se realizará incluso a pedido del juez.

De la redacción del texto procesal penal "toda persona es, en principio, hábil para prestar testimonio, salvo el inhábil por razones naturales", se aprecia una regulación genérica que excluye el testimonio del inhábil por razones naturales, que podría ser relevante, sin mayor tipo de especificación, la cual conviene efectuar.

La configuración legal de dichas razones exclusivas o de exclusión, han sido cuestionadas doctrinariamente. Se ha inquirido, por ejemplo, ¿si la declaración de todos los incapacitados deja de tener utilidad y veracidad? De ahí que la doctrina sea del parecer que "para nuestro legislador, la ciencia y la psicología moderna no existen. Para él, los hombres o están locos o no están locos, nada más" (Nieva, 2010, pp. 264-265).

En función del principio de relevancia, debe priorizarse el ingreso de todo testimonio si es pertinente para el caso y, de presentarse testigos con algún tipo de impedimento físico o psíquico, se deberá determinar si este afectó en algún modo la percepción de los hechos sobre los cuales declara.

Así, por ejemplo, si en un proceso en el que se le imputa a un sujeto el delito de feminicidio, el fiscal presenta la declaración de un testigo que haya escuchado las constantes discusiones y la pelea entre el imputado y su pareja el día de la muerte de la víctima, y el testigo sea invidente, su testimonio al ser relevante será ingresado al proceso en tanto su incapacidad no incide ni impide el conocimiento de los hechos importantes para el esclarecimiento del caso; esto es, su versión respecto a que pudo escuchar que el imputado agredía a la víctima en reiteradas ocasiones.

Al respecto, De Paula Ramos (2019, p. 147) precisa lo siguiente:

Debe analizarse la posibilidad de que los considerados parcial o totalmente incapaces puedan ser testigos (....) un sistema no debe considerar admisible la prueba testifical de una persona cuando la incapacidad pueda eliminar por completo la posibilidad de que, potencialmente, pudiera aumentar o disminuir la corroboración de al menos alguna hipótesis sobre los hechos objeto del proceso. Es el caso, por ejemplo, de una persona que es ciega o sorda cuando el conocimiento de los hechos del caso depende de los sentidos que le faltan o el del testigo que sufre una enfermedad que le impide discernir los hechos objeto del litigio.

Sin embargo, si ese no es el caso la prueba debe ser admitida. Eso puede darse, por ejemplo, en la situación de que una persona con una enfermedad mental tenga discernimiento suficiente sobre los hechos, en cuyo caso deberá admitirse su declaración. 
Por ello, se considera en este trabajo que, si la declaración del testigo considerado inhábil (que adolece de algún tipo de incapacidad física o psicológica) es relevante para el objeto de la causa, la restricción de la declaración del testigo deberá ser evaluada por el juez de investigación preparatoria en la fase de admisión, lo cual implica que:

- La parte que proponga a un testigo con estas características lo especifique concretamente en la audiencia y se indique la situación física y psicológica del declarante.

- El juez analice en qué medida la incapacidad del testigo incide y afecta directamente el objeto de la declaración.

- Si la incapacidad del testigo afecta el objeto de su declaración el juez podrá excluir su testimonio, no obstante,

- Si la incapacidad del testigo no afecta el objeto de su declaración se incluirá y de ser el caso se verificará la idoneidad física o psíquica del testigo recurriendo a otras pruebas como la pericial, la misma que podrá ser ordenada de oficio por el juez.

Por consiguiente, para que el texto del CPP se interprete en función del principio de relevancia del testimonio, procurando el ingreso de toda declaración que posibilite el esclarecimiento de los hechos, deberá ser reformulado. Entonces, la redacción del artículo 162 del CPP sería del siguiente modo (la cursiva es la incorporación propuesta):

1. Toda persona es, en principio, hábil para prestar testimonio, excepto el inhábil por razones naturales, siempre, que estas razones lo imposibiliten para conocer o dar testimonio sobre el objeto de prueba (...).

2. Si para admitir o valorar el testimonio es necesario verificar la idoneidad física o psíquica del testigo, se realizarán las indagaciones necesarias y, en especial, la realización de las pericias que correspondan. Esta última prueba podrá ser ordenada de oficio por el Juez.

\section{ii. Testigos impedidos por ley}

La regla general es que declarante hábil física y psicológicamente atestigüe en el proceso. Sin embargo, el CPP expone una serie de excepciones legales adicionales para apartar un testimonio en salvaguarda de otros valores o intereses. La norma procesal regula los siguientes casos en que se puede inadmitir un testimonio, a continuación: 
a) El testigo no podrá ser obligado a declarar sobre hechos de los cuales podría surgir su responsabilidad penal (artículo 163.2)

La primera restricción del testimonio del declarante es aquella que prescinde de información fáctica de la cual puede inferirse su participación en un hecho delictivo. De ocurrir esta situación en el juicio de admisibilidad, la parte correspondiente presentará y expondrá el objeto sobre el cual versará el testimonio de su testigo; pero, en ningún caso, este podría tratarse de hechos en los cuales se derivaría su participación en un delito.

La prohibición de obligar al testigo a declarar se debe interpretar sistemáticamente con aquel derecho del imputado de abstenerse a declarar (artículo 71.2.d del CPP). Sobre el derecho a la no autoincriminación del imputado, el Tribunal Constitucional peruano en el Expediente $\mathrm{N}^{\circ}$ 03-2005-PI/TC, refiere:

(...) [N]o se encuentra reconocido expresamente en la Constitución. Sin embargo, se trata de un derecho fundamental de orden procesal que forma parte de los derechos implícitos que conforman el derecho al debido proceso penal, este último reconocido en el inciso 3) del artículo 139 de la Constitución. Su condición de derecho implícito que forma parte de un derecho expresamente reconocido, también se puede inferir a partir de la función que los tratados internacionales en materia de derechos humanos (...). Así por ejemplo el artículo 8 o de la Convención Americana de Derechos Humanos, que reconoce expresamente como parte de las "Garantías Judiciales" mínimas que tiene todo procesado, el "g) derecho a no ser obligado a declarar contra sí mismo ni a declararse culpable (...).

Lo mismo sucede con el ordinal "g" del artículo 14.3 del Pacto Internacional de Derechos Civiles y Políticos (...).

Dicho derecho garantiza a toda persona no ser obligada a descubrirse contra sí misma (nemo tenetur se detegere), no ser obligada a declarar contra sí misma (nemo tenetur edere contra se) o, lo que es lo mismo, no ser obligada a acusarse a sí misma (nemo tenetur se ipsum accusare).

La regulación legislativa fundamentada en la protección de derechos fundamentales ha generado oposición por parte de posturas doctrinarias; así, Laudan (2013, pp. 229-230) considera que, cuando un testigo se rehúsa a prestar su testimonio, irrumpe la averiguación de los hechos en el caso. Sostiene sobre los testigos silenciosos que:

[E]l derecho a permanecer en silencio hace más probable que el culpable sea absuelto y que el inocente sea condenado. Esta decisión legislativa, por supuesto, es exactamente la forma opuesta a cómo debería funcionar un sistema cuyo objetivo es la búsqueda de la verdad o la disminución del error. 
En cuanto a la razón que fundamenta la exclusión del testimonio deben hacerse las siguientes precisiones:

- Es evidente que nuestro legislador priorizó el derecho a guardar silencio del testigo por encima de la búsqueda de la verdad, salvaguardando la reserva del conocimiento de hechos que podrían perjudicarlo. Prima, en ese caso, la razón no epistémica de la citada exclusión del testimonio y se encuentra debidamente justificada en la protección de derechos fundamentales.

- No obstante, cabe aclarar que, si la obligación a declarar involucrara algún tipo de acción que violente física o psicológicamente la voluntad del testigo, su exclusión sí estaría fundamentada en razones epistémicas. Ello es así porque un testimonio obtenido mediante algún tipo de violencia sería un testimonio viciado, carente de una mínima fiabilidad y cuya inclusión generaría un desmedro en la determinación de la verdad. Es decir, en este segundo supuesto, su exclusión estaría fundamentada no solo en la protección de derechos fundamentales, sino en razones epistémicas.

A continuación, la legislación procesal penal contempla aquella facultad de los testigos de abstenerse a declarar cuando se encuentren en determinada situación o condición personal. Son los denominados por la doctrina anglosajona como privileges (privilegios), según los cuales:

Se les exime a determinados sujetos de aportar información relevante para el caso, como, por ejemplo: abogados, respecto de la información obtenida de sus clientes, sacerdotes, sobre la información obtenida en confesión, cualquier sujeto respecto de la información que pueda incriminarle, o familiares directos, en cuanto a los datos que puedan perjudicar o beneficiar a esos familiares (Ferrer, 2007, p. 43).

Seguidamente, su análisis.

b) Los declarantes pueden abstenerse de rendir su testimonio cuando tengan una relación conyugal, de convivencia o de familiaridad con el imputado del caso (art. 165.1):

La exclusión de las declaraciones de familiares y personas con vínculo conyugal o similar a un imputado está vinculada a la facultad o derecho de los declarantes de no concurrir al proceso o de que su testimonio no sea incluido en el conjunto de pruebas, bajo el supuesto del vínculo cercano con el investigado en un proceso judicial. Ahora bien, ¿cuál podría ser el fundamento de relegar su testimonio, si se da por supuesta su relevancia? 
Se ha sostenido que las exclusiones de este tipo se fundamentan en el resguardo de las relaciones familiares del declarante con el investigado procesalmente. Laudan expresa que, en más de una ocasión, se ha considerado que, si a través de una prueba testimonial se obtuviera información confidencial, por ejemplo, que es intercambiada entre el investigado y su cónyuge, "la integridad y la viabilidad de tales relaciones serían severamente amenazadas" (2013, p. 231).

La justificación de los privilegios de los familiares, según la postura de MacCormick (1984, p. 171) se fundamentaría en lo siguiente:

Las reglas sobre las relaciones privilegiadas no están desprovistas de una racionalidad. Su justificación es la protección de ciertos intereses y de algunos tipos de relación que son consideradas de una importancia social suficiente como para justificar el sacrificio de ciertas pruebas relevantes disponibles para la administración de justicia.

La exclusión del testimonio de familiares no es de data reciente. En épocas anteriores también se excluyeron testimonios de "personas que pudieran verse influidas emocionalmente en su testimonio que estaría dirigido a pretender beneficiar al imputado de los hechos". No obstante, como bien lo asevera Nieva, sea de una u otra forma, el parentesco, la amistad íntima, entre otros vínculos sentimentales que unen al imputado con el declarante "serían circunstancias que el juez debe tener en cuenta a la hora de valorar el testimonio" (2010, p. 229) y no al momento de admitirlo, posición acorde al principio de relevancia.

En ese entender, si lo que se pretende es proteger las relaciones o vínculos, familiares, conyugales o de amistad del imputado, deberían establecerse otros instrumentos que los resguarden pero que no sacrifiquen la inclusión de una prueba testimonial de gran relevancia, como podría ser la declaración proveniente de un familiar, pues su separación perjudica la formación de un conjunto probatorio conveniente para esclarecer los hechos.

Al respecto, como lo refiere De Paula Ramos (2019, p. 147):

No parecen haber razones epistémicas que impidan que se tome la declaración a personas que sean amigo íntimo o enemigo manifiesto, cónyuge, compañero o familiar cercano. De nuevo se trata de una confusión entre la valoración y la admisión; además de un juicio previo injustificado, una generalización ilegítima. Pese a que legítimamente se pueda sospechar que un testigo tenga algún sesgo cognitivo, por ejemplo, a favor de la parte que es su amiga íntima, esto no significa que a priori pueda decirse que su testimonio nunca podrá, potencialmente, ser sincero o verdadero ni que no se podrá aprovechar una sola información de lo que se afirme. 
La posibilidad que se brinda al testigo de abstenerse a declarar cuando tenga una vinculación con el imputado ocasiona un desmedro al esclarecimiento de los hechos en tanto se fundamenta en razones no epistémicas no justificadas, por lo siguiente:

- Si lo que se pretende es la protección del vínculo familiar, no se encontraría justificada esta regla, pues se parte del supuesto de que su declaración en todos los casos podría perjudicar al imputado y, en consecuencia, ir en desmedro de su relación familiar. Pero, obviamente, no siempre se dará este supuesto; por el contrario, la versión de un testigo familiar incluso podría favorecer la hipótesis exculpatoria del procesado.

- Si lo que se pretende con la abstención del testimonio es evitar que su versión esté dirigida a beneficiar al imputado, tampoco dicha excepción estaría justificada porque presupone que el testigo posea sesgos emocionales que siempre conllevaría a que emita una declaración favorable al imputado, y no está acreditado objetivamente que ello siempre ocurra.

Cualquiera sea el caso, la etapa de admisión de prueba no es el momento adecuado para apreciar si la versión del testigo familiar perjudicará al imputado y concluir de ello que las relaciones o lazos de familiaridad se afecten; tampoco la admisión es el momento oportuno para dudar de la declaración de un testigo por la sola razón de que es un familiar del imputado. La apreciación de la fiabilidad de un testimonio siempre deberá efectuarse en la fase de valoración, nunca en la admisión probatoria.

Como lo advierte la doctrina mencionada, en realidad, es un juicio de valoración suponer que la declaración del testigo familiar será siempre a favor del imputado, especialmente, si se tiene en consideración que el objeto u objetos sobre los cuales puede pronunciarse para el esclarecimiento de la causa son diversos y será el juez del juicio quien le otorgará el valor a favor o en contra de la tesis de defensa. En ambos casos, corresponderá al juez la valoración de sus declaraciones y el valor que le otorgue al testimonio en función de los otros medios de prueba que se presenten.

Por lo tanto, no existiría una justificación adecuada y suficiente para su exclusión. Esto significa que la política legislativa de brindar la facultad a los familiares de declarar es contraepistemológica y conviene que sea reformada, de tal forma que promueva la inclusión de las declaraciones de aquellos testigos que tengan vinculación familiar y/o sentimental con el imputado.

El texto procesal (artículo 165 del CPP) debería ser reformulado del siguiente modo (la cursiva es la incorporación propuesta): 
1. No deberán abstenerse de rendir testimonio el cónyuge del imputado, los parientes dentro del cuarto grado de consanguinidad o segundo de afinidad, y aquel que tuviera relación de convivencia con él. Se extiende esta obligación, en la misma medida, a los parientes por adopción, y respecto de los cónyuges o convivientes aun cuando haya cesado el vínculo conyugal o convivencial.

c) El CPP también prevé que "deberán abstenerse de declarar, con las precisiones que se detallarán, quienes según la Ley deban guardar secreto profesional o de Estado" (artículo 165.2):

Seguidamente el CPP en el artículo 165.2.a regula la siguiente excepción:

Los vinculados por el secreto profesional no podrán ser obligados a declarar sobre lo conocido por razón del ejercicio de su profesión, salvo los casos en los cuales tengan la obligación de relatarlo a la autoridad judicial. Entre ellos se encuentran los abogados, ministros de cultos religiosos, notarios, médicos y personal sanitario, periodistas u otros profesionales dispensados por Ley expresa. Sin embargo, estas personas, con excepción de ministros de cultos religiosos, no podrán negar su testimonio cuando sean liberadas por el interesado del deber de guardar secreto.

En este caso, deben abstenerse de declarar aquellos profesionales que conocen determinados hechos con motivo del ejercicio laboral. Asimismo, se dispone que ninguno de estos podrá ser obligado a declarar. Entre la lista de profesionales se encuentran, por ejemplo, los abogados, ministros de cultos religiosos ${ }^{4}$, notarios ${ }^{5}$, médicos ${ }^{6}$ y personal sanitario, periodistas ${ }^{7} u$ otros profesionales dispensados por ley expresa.

Si se considera la abstención del abogado de revelar la información que obtuvo de su cliente, se podría afirmar que, en principio, toda defensa para

4 El Código de Ética Profesional para líderes de la Iglesia, contempla en el apartado C.1.1, que "la información que se revela a un ministro de la Iglesia durante el desarrollo de la consejería, dirección espiritual o cualquier otro contacto profesional "debe mantenerse en la más estricta confidencialidad".

5 El Código de Ética del Colegio de Notarios del Perú, instituye en el artículo 4 que "el secreto profesional se trata de un derecho y un deber del notario".

6 El artículo 89 del Código de Ética de Deontología del Colegio Médico del Perú, prevé que "el deber del médico de mantener el secreto profesional con el fin de proteger el derecho paciente a la confidencialidad de los datos que le ha brindado, los mismos que no puede divulgar, salvo que el paciente exprese su autorización".

7 El artículo 7 del Código de Ética de Periodistas del Colegio de Periodistas del Perú prevé la exigencia de "guardar el secreto profesional sobre las fuentes de información". 
ser eficaz debería contar con la mayor cantidad de información posible sobre el hecho y esta información la tendrá que proporcionar el patrocinado. Este último tendría la seguridad de que todo dato que le revele a su defensa servirá para que elabore una estrategia que lo beneficie y, por supuesto, se mantendría en reserva en función de la regulación del CPP.

Si este no fuera el caso y, por el contrario, el abogado defensor divulgara la información confidencial de su cliente ante los tribunales, ello podría ocasionar que, en adelante, otros imputados no entreguen libremente a sus abogados toda la información que conocen, lo que, a su vez, traería como consecuencia que en procesos futuros no se cuente con información verdadera o, si se cuenta con información, esta probablemente sería incompleta o falsa. Lo mencionado dificultaría no solo la labor del juez en el esclarecimiento real de los hechos, sino también, en el peor de los casos, perjudicaría la situación del imputado.

La excepción al testimonio que reserva el secreto profesional (de los abogados y los profesionales que la norma refiere) cuenta con una razón epistémica.

\subsubsection{Excepciones por la información que puede revelar el testigo}

Como segunda clase de excepción a la inclusión de testimonios, se pueden identificar algunas que inciden de modo concreto en el tipo o contenido de información que brindan los testigos.

Se ha sostenido en más de una ocasión que "el Derecho Penal expone que 'toda prueba que presenta un individuo' es también prueba del Estado" (Wigmore, 1942, p. 2192, citado en Laudan, 2013) ${ }^{8}$. Sin embargo, esta aserción parece flexibilizarse, porque como lo acota el profesor estadounidense, Laudan, "existe cierto tipo de información que goza de un estatus jurídico especial. En tanto que, aquellos que poseen tal información no pueden ser obligados a testificar al respecto, ni sancionados por no hacerlo" (2013, p. 230) [Énfasis agregado].

Estos casos se pueden ubicar en las siguientes exclusiones legales que prevé el CPP (el énfasis es nuestro):

- El testigo policía, militar o miembro de los sistemas de inteligencia del Estado no pueden ser obligados a revelar los nombres de sus informantes (artículo 163.3).

$8 \quad$ Wigmore (1942, p. 2192) plantea que "por más de tres siglos se ha reconocido como máxima fundamental que la comunidad tiene derecho a las pruebas que tiene cualquier sujeto" (citado en Laudan, 2013, p. 230). 
- Deben abstenerse de declarar aquellos sujetos que deban guardar el secreto de Estado sobre hechos que pudieron conocer determinados por el ejercicio de su profesión (artículo 165.2.b).

En ambos casos, el núcleo del privilegio es la información específica que obtiene el agente declarante producto de la actuación de su profesión. ¿De qué información puede tratarse? En el primer caso, se describe que los datos sobre la identificación de los informantes no pueden ser revelados por aquellos testigos policías, militares o de los sistemas de inteligencia del Estado peruano que hayan involucrado a estos informantes en algún caso concreto.

En el supuesto de la declaración del policía, militar o miembro del sistema de inteligencia, la exclusión podría estar fundada en la seguridad personal de los miembros informantes de la policía, fiscalía e instituciones de inteligencia del Estado peruano, que, en su mayoría, actúan bajo una identidad protegida que permite que indaguen detalles y encuentren información que, de modo público, sería imposible lograrlo.

Uno de estos ejemplos podría tratarse del agente encubierto (artículo 341 del (PP). Sobre esta restricción, debe tomarse en cuenta que la reserva de la identidad de los agentes informantes permite que la información con la que cuenten los órganos de la policía - por ejemplo- sea mayor en comparación de si los informantes no la aportaran. En cambio, si se optara por eliminar esta restricción podría ocasionar que en casos futuros los agentes que poseen dicha información relevante se desistan de hacerlo por temor a ser expuestos públicamente o, en el peor de los casos, sean agredidos por los presuntos perjudicados con su información y ello devendría en un perjuicio para la formación del conjunto probatorio ${ }^{9}$.

Se trata, entonces, de una regla justificada bajo una razón epistémica porque la protección de los testigos incide en salvaguardar los datos que posiblemente ingresen al proceso mediante los informantes.

En el segundo supuesto, se fundamenta en prohibir a aquellos funcionarios y servidores públicos revelar la información clasificada como secreta o reservada. Al respecto, el Código de Ética de la Función Pública, Ley N²7815, del 12 de agosto de 2002, prevé, en su artículo 3, que el funcionario público:

$9 \quad$ Al respecto, el CPP prevé, en el artículo 341.2, que la disposición que aprueba la designación de agentes encubiertos debe consignar el nombre verdadero y la identidad supuesta con la que actuarán en el caso concreto. Establece que la decisión debe ser reservada y conservada fuera de las actuaciones con la debida seguridad. 
Debe guardar reserva respecto de hechos o informaciones de los que tenga conocimiento con motivo o en ocasión del ejercicio de sus funciones, sin perjuicio de los deberes y las responsabilidades que le correspondan en virtud de las normas que regulan el acceso y la transparencia de la información pública.

La norma estipula que, si estos funcionarios son llamados a declarar, deben dar a conocer su situación o condición a la autoridad judicial o fiscal, y la carga de confirmar esta información sobre su condición recae en el ministerio del sector correspondiente, el cual debe determinar si los datos que se requieren de los servidores estatales se encuentran dentro de los alcances de las excepciones establecidas en el Texto Único Ordenado de la ley de materia. En ese último caso, el testigo que tenga la información calificada como un secreto de Estado, no puede ser obligado a divulgarla a los operadores de justicia.

En definitiva, si esto es así, las partes no podrán proponer como un medio de prueba la declaración del policía que tenga por objeto revelar la identidad de su informante, ni la declaración del funcionario público del Poder Judicial que tenga información reservada y catalogada según su ley orgánica como un secreto de Estado. Si el objeto de prueba versa sobre estos aspectos, en los términos legales dispuestos por el CPP, debe ser excluida del caudal probatorio, pese a su potencial relevancia para la averiguación del supuesto factico imputado. Esta decisión tiene una orientación justificada en un criterio epistémico.

\section{CONCLUSIONES}

La etapa de admisión es uno de los momentos primordiales del proceso penal, se constituye en la fase de conformación de los elementos de juicio y está dirigida por el juez de investigación preparatoria quien, en este momento procesal, ejerce sus poderes o facultades de admitir, inadmitir o rechazar las pruebas propuestas. La admisión es el ejercicio de un poder probatorio judicial.

El CPP prevé en los artículos 155.2 y 352.5 la configuración legal de la etapa admisoria. Establece como presupuestos de ingreso al proceso que toda prueba presentada debe ser pertinente, útil y conducente, asimismo que ofrezca el probable aporte de la prueba al objeto que se pretende probar. En realidad, el contenido conceptual de pertinencia, utilidad, conducencia es el mismo y significa que todo elemento de juicio que pretenda ingresar al sustrato probatorio debe generar un impacto - positivo o negativo- en este, para confirmar o debatir la hipótesis en cuestión o el objeto de prueba, una prueba con estas características es una prueba relevante que debe ser incorporada al proceso, de lo contrario deberá ser rechazada. 
El principio de relevancia es el fundamento epistémico de la fase de admisión porque, en función de este, toda prueba que genere un aporte al conocimiento de la verdad de la hipótesis a probar deberá ingresar al conjunto de pruebas. La fase de admisión se guía por un fin epistémico a través de la inclusión de toda prueba relevante que permitirá que, una vez valoradas, la probabilidad que la decisión sea acertada será mayor.

El CPP prevé una lista de excepciones que no siempre estarán justificadas desde un enfoque epistémico. Se ha clasificado la inadmisión de testimonios en dos tipos de razones: naturales y por la ley. La primera refiere que no pueden proponerse como testigos, en el proceso penal, personas que carecen de idoneidad física o psíquica necesaria para declarar; sin embargo, antes de tomar una decisión de exclusión la parte que proponga a un testigo con dichas características debe especificar concretamente en la audiencia y en el escrito fiscal la situación física del declarante y en qué medida inciden sus patologías en su declaración. Es decir, en función del principio de relevancia, debe priorizarse el ingreso de su testimonio por lo que corresponde determinar si la declaración del testigo involucra o no el uso de la capacidad física o psicológica de la cual carecía, si este es el caso, debería ser inadmitido; de lo contrario, se admitirá en todos los casos.

En cuanto a la inadmisión de testigos por estipulación de la ley, el artículo 163.2 del CPP establece como primera restricción del testimonio respecto de aquella información fáctica de la cual podría derivar su participación en un hecho delictivo. Esta decisión de exclusión no se corresponde con razones epistemológicas dado que se excluye una prueba relevante, pues un testimonio que verse sobre estos extremos sería poderosamente pertinente para el esclarecimiento del caso; no obstante, se encuentra debidamente justificada en la protección de derechos fundamentales como la no autoincriminación.

Luego, nuestro CPP contempla los Ilamados privilegios. Así, el artículo 165.1 del CPP prevé la exclusión de las declaraciones de familiares y personas con vínculo conyugal o similar a este con el imputado del proceso, esta exclusión no responde a un fin epistémico del proceso; por el contrario, empobrece el sustrato probatorio y es una opción legislativa no justificada que conviene ser reformada.

EI CPP regula en el artículo 165.2.a la exclusión del testimonio de profesionales que, por motivo del ejercicio de su función, conocieron de circunstancias sobre el objeto del proceso, tales como los abogados, médicos, religiosos, entre otros. Si bien se trata de la exclusión de datos importantes para el esclarecimiento de los hechos, sí es una decisión que se orienta a un efecto epistémico 
futuro, en tanto que la reserva de información fomentaría que, en procesos posteriores y distintos, los imputados brinden información detallada a los profesionales y el caso se resuelva óptimamente.

Finalmente, la ley procesal penal excluye a determinados testigos por el tipo de información que puedan expresar; así, el testigo policial, militar o miembro de los sistemas de inteligencia del Estado no pueden ser obligados a revelar los nombres de sus informantes (artículo 163.3) y también se abstienen los que deban guardar el secreto de Estado (artículo 165.2.b). Ambas restricciones se guían bajo una finalidad epistémica, por los mismos efectos epistémicos en casos futuros que en el supuesto anterior.

La presente investigación solo se constituye en una propuesta de reforma legislativa con base en el reconocimiento de razones epistémicas y no epistémicas de la normativa que regula la prueba testimonial. Sin embargo, conviene, en estudios posteriores, identificar algunas reglas de admisión que podrían ser incorporadas atendiendo al principio de relevancia; pero, especialmente, al empleo de conocimientos especializados como la psicología del testimonio, cuyos aportes podrían orientar en el juicio de admisibilidad peruano.

\section{LISTA DE REFERENCIAS}

Abel, X. (2012). Derecho probatorio. J.M. Bosch Editor.

Armenta, T. (2012). Sistemas procesales penales. Marcial Pons.

Contreras, C. (2015). La valoración de la prueba de interrogatorio. Marcial Pons.

Cuello, G. (2008). Derecho probatorio y pruebas penales. Editorial Legis.

Dei Vecchi, D. (2019). Admisibilidad de las pruebas: ¿criterios epistemológicos o procesales? En R. Cavani (coordinador), Garantías procesales y poderes del juez. Zela.

De Paula, V. (2013). Derecho fundamental a la prueba. Gaceta Constitucional.

De Paula, V. (2019). La prueba testifical. Del subjetivismo al objetivismo, del aislamiento científico al diálogo con la psicología y epistemología. Marcial Pons.

Duce, M. (2013). La prueba pericial. Aspectos legales y estratégicos claves para el litigio en los sistemas procesales penales acusatorios. Ediciones Didot.

Ferrer, J. (2005). Prueba y verdad en el derecho. (2a ed.). Marcial Pons.

Ferrer, J. (2017). Los poderes probatorios del juez y el modelo de proceso. Revista De La Maestría En Derecho Procesal, 7(2), pp. 137-164. http://revistas.pucp. edu.pe/index.php/derechoprocesal/article/view/19697 
Gascón, M. (2006). Freedom of proof. El cuestionable debilitamiento de la regla de exclusión de la prueba ilícita. En J. Ferrer et al. (2006), Estudios sobre la Prueba. Universidad Nacional Autónoma de México.

Jauchen, E. (2004). Tratado de la prueba en materia penal. Rubinzal Culzoni Editores. Laudan, L. (2013). Verdad, error y proceso penal. Un ensayo sobre epistemología jurídica. Marcial Pons.

Montero, J. (2000). Procedimiento probatorio (la grandeza de la sumisión a la ley procesal). En J. Montero (director), La prueba. Consejo General del Poder Judicial.

Nieva, J. (2010). La valoración de la prueba. Marcial Pons.

Oré, A. (2016). Derecho procesal penal peruano. Análisis y comentarios al Código Procesal Penal. (Tomo II). Gaceta Jurídica.

Parra, J. (2013). Manual de derecho probatorio. (18a ed.). Ediciones del Profesional LTDA.

San Martín, C. (2020). Lecciones de derecho procesal penal. (2ª ed.). Inpeccp.

Talavera, P. (2009). La prueba en el nuevo proceso penal. Academia de la Magistratura.

Taruffo, M. (2011). La prueba de los hechos. (4a ed.). (trad.). Trotta.

Vázquez, C. (2015). La admisibilidad de las pruebas periciales y la racionalidad de las decisiones judiciales. DOXA, Cuadernos de Filosofía del Derecho, 38, pp. 101-130. Biblioteca Virtual Miguel de Cervantes. http://www. cervantesvirtual.com/obra/la-admisibilidad-de-las-pruebas-periciales-y-la-racionalidd-de-las-decisiones-judiciales-847731/. https://doi. org/10.14198/DOXA2015.38.04

Vázquez, C. (2017). Los retos de las pruebas periciales a partir del nuevo Código Nacional de Procedimientos Penales. Apuntes desde la epistemología jurídica. Anuario de Filosofía y Teoría del Derecho, 11, pp. 341-378. https://revistas. juridicas.unam.mx/index.php/filosofia-derecho/article/view/11077/13099 